\title{
COVID-19 Induced Changes on Lifestyles Education and Socio-Economic Activities in West African States: Recovery Strategies for Post Pandemic Era
}

Oladotun Opeoluwa Olagbaju (Corresponding Author)

College of Education and Social Sciences, Legacy University, The Gambia

Email: dotunolagbaju@yahoo.com

\section{Oladotun Emmanuel Awosusi \\ College of Arts, Law, Administration and Management, Legacy University, The Gambia}

\author{
Oluwatobi Emmanuel Shaib \\ College of Education and Social Sciences, Legacy University, The Gambia
}

\author{
Article History \\ Received: February 28, 2020 \\ Revised: March 25, 2020 \\ Accepted: April 3, 2020 \\ Published: April 5, 2020 \\ Copyright @ 2020 ARPG \& \\ Author \\ This work is licensed under \\ the Creative Commons \\ Attribution International \\ (9) (1) \\ BY: Creative Commons \\ Attribution License 4.0
}

\begin{abstract}
The outbreak and subsequent spread of COVID-19 to the West African sub-region have brought significant changes to the different aspects of our lives and grounded educational and socio-political and economic activities of ECOWAS member states. The pandemic has exposed the poor state of the health systems and shortage in medical supplies and protective gears to cope with the health emergency. In response, strict restrictions were put in place to curb the spread of the virus and these have drastically affected peoples' lifestyles. However, there has been huge increase in the use of technology in business, education, religion and other activities as people adapt to the changing times in the sub-region. It is the argument of this paper that things cannot return to the way they were before the pandemic, but West African states must strategically plan for the Post COVID-19 era to survive the massive wave of unemployment, socio-economic meltdown and changes in lifestyle. The paper concluded that while the fight against the virus in the sub-region was not collective, post-pandemic recovery must be coordinated, strategically plannedamong member states. It was recommended that the governments should be flexible enough to retain the use of ICT and technology alongside the conventional ways of doing things in the post-pandemic era.
\end{abstract}

Keywords: COVID-19 pandemic; West africa; Education; Socio-economic meltdown; Recovery strategies.

\section{Introduction}

The history of outbreaks of pandemics and contagious diseases is as old as the existence of mankind. Thee novel Corona Virus otherwise referred to as COVID-19 was first discovered in 2019 in the Chinese city of Wuhan following which the pandemic has spread like wildfire across continents, constituting global health crises with attendant effects on politics, economies, education and lifestyles globally. The catastrophic effects of the pandemic in terms of the daily geometric increase in the number of confirmed infections and deaths prompted the World Health Organization (WHO) and political leaders across the world to initiate strict measures. The interventions to contain the spread of the COVID-19 pandemic included the travel restrictions, massive testing, aggressive contact tracing, establishment of isolation centres and quarantine procedures, huge investments in medical supplies, ventilators, and training of medical practitioners, social distancing, locking down societies, among others.

Other efforts at mitigating the spread of the virus globally have been in the areas of collating data daily, developing effective vaccines and preventive measures to contain the spread or surge in infected cases. The strict procedures introduced to protect lives and curb the spread of the novel Corona virus portend a major shift in peoples' lifestyles globally in terms of social relations, economy, politics and education to mention but a few. In most African states, the threats of the pandemic were not taken serious early enough and so, the response was weak. While other continents were seriously battling the pandemic, most African states were still going about their normal daily sociopolitical and economic routines. The first case of the pandemic was recorded in Egypt on February 14, 2020 and the first confirmed case in sub-Saharan Africa was in Nigeria (BBC News, 2020). Maclean (2020), laments that most of the index cases of Covid-19 in Africa were imported from Europe and America rather than China, where the virus originated.

The possibility of Africa becoming the epicentre of the pandemic has become a major concern to professionals and experts across the globe due to the fragile health systems characterized by inadequate funding, ineffective data management system, inadequate training of healthcare workers and unavailability of modern medical equipment. Almost all the West African states have recorded confirmed cases and deaths with some recoveries. In line with the practices in containing the pandemic, countries in the sub-region have instituted measures such as travel bans or restrictions, closure of land and sea ports, grounding of all non-essential flights or movements, contact tracing, massive sensitization of citizens on the nature of the virus, isolation or social distancing, disinfecting public places, shutting down of schools, religious and other public places. Because of the 'lockdowns' and restriction of people's 
movement in most West African states, most businesses have gone cashless with a 70\% rise in Point On Sales(POS) transactions in Nigeria in March, 2020 according to a report by the Nigerian Inter-Bank Settlement Scheme (NIBSS) (Adesanya, 2020). Also, the educational system has evolved from conventional classroom instruction to eLearning channels such as Google or virtual classroom, radio and television teaching sessions.

However, there has been little effort in the areas of massive or early testing and provision of Personal Protective Equipment (PPE) for frontline health workers in West Africa. This led to increase in the toll of Covid-19 cases across Africa which prompted strict restrictions that have affected peoples' economy and lifestyle in many countries within the continent. As expected, several small scale businesses, schools and public facilities were shutdown to promote social distancing and reduce person-to-person contacts that feeds the virus. Such measures have come at a great cost to the survival of the businesses and local and national economy. Therefore, the continent of Africa and West African sub-region in particular should brace up for large scale unemployment, socio-economic meltdown and massive changes in the peoples' lifestyles in the post pandemic era.

Unlike the countries in Europe, Asia and America, most West African states (either the Francophone or Anglophone countries) share strong colonial and sub-regional experiences through the Economic Community of West African States (ECOWAS) charter agreement or protocol among them which allows free movement of individuals across the sub-region without a visa for an initial period of 90 days. Therefore, there is high traffic of people and trades across the West African states thereby making the spread of the virus and socio-economic impact of the pandemic to cause a chain reaction on the economy of the sub-region. In essence, West African states need not only to brace up to contain the pandemic, conquer it and flatten the curve but also to develop recovery strategies to survive the post-COVID-19 global dynamics with attendant changes in lifestyles, education and possible socioeconomic meltdown.

The impacts of this pandemic are being felt across all sectors of the global economy, and Africa continent would not be spared given the nuances of globalization and economic interdependence. The most hit sectors are that aviation industry, entertainment industry, sports, education etc. with the overall impact on the global economy and peoples' lifestyles. In addition, the pandemic has affected global price of crude oil which dropped to as low as $\$ 30$ and could dropped further without the intervention of the Organization of Petroleum Exporting Countries (OPEC) (United Nations Office on Drugs and Crime, 2020). The drop in the price of crude oil portends huge deficits in the expected incomes of nations that rely on oil export and Nigeria which is a 'big brother' to other countries in West Africa is already reconsidering its budgetary commitments for 2020. Similarly, the International Monetary Fund report International Monetary Fund (2020) has warned that the three major economies in Africa namely Nigeria, South Africa and Angola are at the brink of total collapse.

Nigeria accounts for more than $60 \%$ of the economy of the sub-region and remains the major market for virtually all the 15 Economic Community of West African (ECOWAS) member States (Karaki and Verhaeghe, 2017).With Nigeria being the power house in the West African bloc, the implication is the spill-over of the economic recession across the sub-region because "whenever Nigeria sneezes, West Africa catches a cold". More so, the outbreak of the pandemic coincided with the period most of the countries are trying to adjust to the economic realities of the abrupt closure of Nigeria's borders against its immediate neighbours of Benin, Chad, Niger and Cameroun since August 2019 in a bid to protect its wobbling economy and salvage the increasing insecurity in the country.

Given the ravaging effect of the global health crisis (COVID-19 pandemic) on socio-political landscape, national economy, education and peoples' lifestyle vis-à-vis the fragile nature of the healthcare systems, economies, democracies and education in most West African states, massive lifestyle changes are imminent. Therefore, this paper attempts to project into the post COVID-19 pandemic era in West Africa with its implications for education, socio-economic realities and lifestyles changes in the sub-region and proffer recovery strategies that can ameliorate the frustrations of member states.

\section{Management of COVID-19 Pandemic in Africa: The West African Experience}

Africa is a continent that is always on the brink. The continent is notoriously known for diverse kinds of sociopolitical and economic crises, ethnic-based unrests and terrorist or militia attacks, poverty and institutional collapse with increasing effects on the polity, economy, education and daily lives. In the face of these challenges, respective African states are making unrelenting efforts to build sustainable domestic structures for national development and by extension continental stability amidst the prevailing circumstances. The import of the novel Corona Virus pandemic has compounded the prevailing difficulty situations and altered peoples' way of life in most African states. Although most Africans were initially unperturbed by the spread of COVID-19 globally, the outbreak of the pandemic in the continent ushered several West African states into panic mode and undertaking drastic actions to mitigate the impact on peoples' lives and the economy.

Fighting or curtailing the spread of the virus is particularly difficult in the West African sub-region because of the high rate of poverty and illiteracy/ignorance. In fact, some Africans erroneously believed that the pandemic is a 'White-Man's Disease' that cannot survive in the tropical region of Africa. Also, there were several reports and misinformation that the virus cannot resist heat (Rumours and Facts, 2020), and as such, it was believed that it cannot survive under warm temperature above 26-27 degrees. This made many people believe that the spread of the virus will be very slow if it eventually ventures into Africa because most countries are at average temperature of between 25-35 degrees. Ironically, the virus has since infected and killed Africans in their hundreds in various 
countries with Senegal, Burkina Faso, Gambia, Ghana and Nigeria among others battling with geometric daily increase in figures of deaths and infections.

Since the outbreak of the pandemic in the continent, over 54 African countries have recorded cases of COVID19 infections with several deaths on a daily basis. For instance, the number of confirmed cases in Africa as at March 17, 2020 was 450, and by April 16 of the same year, it has risen to over 16,200 cases (Africa Centre for Disease Control, 2020). Indeed, Africa is gradually becoming the new epicentre of the pandemic because of numerous problems that include inadequacy in the quality and quantity of information available on the management of the virus, lack of a valid system of data management and necessary political instrument or structure. The extent of the disruptions to peoples' lifestyles is yet to be fully seen at this point, however, the impact is already evident on individuals and households, especially the vulnerable within the West African states.

According to RAND Corporation report (2016) cited in Devecioglu (2020), at least 22 African countries are among the list of 25 nations that are most vulnerable to infectious diseases in the world. From all indications, Africa is likely to become the new hub of the Covid-19 spread unless serious efforts are geared towards containing the pandemic and flattening the current curve. So far, most West African states have deployed border diplomacy in terms of borders closure, isolating or quarantine of travellers from countries with reported cases of the virus at the points of entry and placing of travel bans to and from countries in Asia, Europe and America. Also, increase in the spread of the pandemic globally has necessitated the closure of land borders across West African states in spite of the pre-existing trade agreements, pacts, policies and subsisting ECOWAS protocols in terms of free movement of persons and goods. The outbreak of Covid-19 in the West African sub-region has many socio-economic activities on hold across the region.

To contain the spread of the pandemic, most national governments with the concerted efforts of various national disease control agencies, African Centre for Disease Control (ACDC) and World Health Organization (WHO), are taking various measures through public awareness on social media networks on the use of nose-masks, regular hand washing with sanitizers and social distancing. Given the comatose state of health facilities across the sub-region, the limited and ill equipped health facilities lack the required human and medical resources to contain the virus. Therefore, most countries in the West African countries sub-region adopted proactive measures such as declaring National Emergencies to enforce social distancing and the lockdown of public places and social gatherings such as schools, churches, mosques, some markets not dealing with food and medical supplies.

Similarly, some of the inmates and detainees awaiting trials in the congested correctional centres in West Africa were hurriedly released to decongest the prisons and contain the spread of the virus considering the poor hygienic conditions and space in prison facilities. For instance, the Nigeria released over 2500 prisoners, Niger released about 1540 inmates; Ethiopia released over 4000 inmates among others cases (Hanafi, 2020). Other efforts aimed at mitigating the spread of the virus and provide treatments for COVID-19 patients led to the establishment of several improvised isolation centres such as hotels, stadia, camp grounds, hostels and other public places that are mostly illequipped and poorly secured. The poor state of these make-shift isolation facilities was responsible for the escape people confirmed to be infected with the virus in West African countries like Nigeria, Senegal, and the Gambia.

In addition, COVID-19 testing kits and Personal Protective Equipment (PPE) for healthcare workers are grossly not enough; therefore, testing across West Africa is selective because it is only done for persons with recent travel history and those people that have close contacts with such persons after returning. This is also compounded by high level of illiteracy and ignorance as persons with the symptoms of the virus are usually reluctant to declare it for fear of being isolated, quarantined or stigmatized. The fight against COVID-19 in West Africa has been tainted by 'secret diplomacy', lack of transparency and irresponsibility of most ruling governments in the sub-region. This has led to several conspiracy theories by some Africans that the virus is a hoax to get foreign loans and aids to be embezzled by political office holders.

There are also scepticisms about the number of acclaimed cases daily which some people feel are deliberately being inflated to draw the empathy of the international community and donors. This perception as well as illiteracy, poverty and lack of responsible governments account for the non-compliance of some Africans to the 'stay-at-home' and 'lockdown' preventive approaches to the spread of pandemic. In Ghana, Nigeria, Gambia and some other West African countries, the compliance levels are very low until security agencies stepped in to enforce compliance, which led to some killings in the South-Eastern part of Nigeria and some other countries by security agencies. Also, the refusal of most African governments to provide adequate palliatives for their respective citizens in spite of receiving financial donations from stake holders, charity organizations and business moguls, pose a serious threat to the lockdown preventive measures, as some prefers to go out and contract the virus than dying of hunger at home. Failure of the government to provide palliatives for the masses in the face of the lockdown is partly responsible for the records of crime in some major cities of some West African states.

In sum, the inability of governments to contain the pandemic in West Africa through self-effort has propelled countries like Nigeria, Burkina Faso, among others to seek the assistance of China, which is believed to have overcome the virus, to provide them with some Chinese Medical professionals in battling the pandemic. No doubt, the numerous efforts to flatten the curve of infections and deaths in West Africa are commendable, but most of the efforts from planning to implementation were mostly adopted from Europe and America without any conscious effort to integrate the environmental dynamics and cultural configuration of the West African states. Apparently, the environment, cultural ideologies, people and socio-economic dynamics of Africa are somewhat parallel to other continents. Therefore, adopting 'foreign' preventive mechanisms without aligning such to the local realities would have dire implications for education, socio-economic status and people's lifestyles in the post COVID-19 era in West Africa. 


\section{COVID-19 Pandemic In West African: Implications for Education Socio- Economic Status and Lifestyles}

The pandemic is mostly spread by bodily contact with an infected person or the cough droplets and other fluids of the infected and so, measures to contain the virus has mostly been through (self) isolation and social distancing. The threats of spreading the virus remain as long as people move it because human beings are social animals that relate and migrate from one place to another. Safety is only guaranteed when people maintain high sanitary standards and keep reasonable distances from the infected, but this cannot be effectively done without strict restrictions and regulations. Therefore, governments in the West African states instituted strict lockdown measures such as curfews, ban on social gathering, shutdown of learning and religious activities in schools and worship centres respectively among other restrictions.

The policy on social distancing and the lockdown of public places and business have hampered the livelihood of people and economic activities across West African States. In countries like Senegal, Nigeria, Burkina Faso and the Gambia, the tourism and aviation industries had to shut- down totally because hotels, restaurants, night clubs and other businesses like that were closed because of the pandemic. Football leagues and major markets were closed down. There are new restrictions on the number of passengers that commercial vehicles are allowed to convey per time, also, there is a new culture of san sanitation through massive disinfectant of public places on daily basis to curb the spread of the virus. Offices and other non-essential service providers were mandated to either provide hand sanitizers or soap and water within their premises for people to practice routine hand washing all in a bid to reduce the spread of the virus.

The implication of this is that it has brought huge changes to peoples' lifestyle across the sub-region because COVID-19 has affected all aspects of our lives and redefined conventional approaches in education, politics, economy, communication and businesses. The West African sub-region has some of the poorest and less developed countries in the continent and the pandemic has dire implications for the socio-economic status and lifestyle patterns of the people, especially the vulnerable citizens of such countries. The current lockdown imposed by governments in the West African sub-region has negatively affected the Pre-COVID-19 economic, social, and security structures of ECOWAS member states. Socially, there are new forms of non-contact greetings with the elbows and the use of face masks and hand sanitizers have become trendy.

Similarly, the numerous efforts to contain the spread of the pandemic through public awareness have been largely via the social media. There has been an unprecedented increase in the use of the Information and Communication Technology (ICT) for socializing, cashless business transactions (Adesanya, 2020), entertainments and education. In a bid to ensure that learning is unperturbed, several institutions of learning have adopted the use of eLearning materials and other eCoursewares to keep students engaged at home. Also, the entertainment industries adapted the eConcert channels to sustain the interest of fans, virtual sports and betting have become popular and there is increase in courier or home delivery of non-essential services all because of the changes brought by the COVID-19 pandemic. Overall, people have learned and are learning new things everyday as they adapt to the changes in social order brought by the virus.

Apart from these positive implications of the pandemic on education, socio-economic status and lifestyles of people in West Africa, the spread of the virus has adversely affected people's life, especially the vulnerable and poor West Africans. The upsurge in the use of ICT has also increased the cybercrimes and activities of fraudsters online (United Nations Office on Drugs and Crime, 2020). Since the lockdown began, families have been forced to stay together and there has been a sharp increase in domestic violence against women and the girl child. United Nations Women (2020) report on COVID-19 posits that over four billion people are in form of lockdown or the other as a result of the pandemic and laments the increase in domestic violence against women during the current lockdown across the globe. Similarly, there has been a rise in crime rates because most people are not allowed to go out and work to earn money fortheir daily upkeep and the government provided little or no palliatives for the people that were asked to stay at home.

In addition, other categories of workers in the sub-region who earn their living on a daily basis such as traders, masons, menial or casual workers, artisans and farmers are left idle and hungry in their homes because of the lockdown. The idle mind is a devil's workshop and these hungry youths could be tempted to embrace crime in a bid to survive the hard times. Similarly, coupled with the hurried released of inmates from prisons in most of the West African states contributed to the rise in theft, armed robbery, and insecurity during the lockdown. Although arrangements were made for palliatives that will cushion the effect of the lockdown on the vulnerable members of the society, especially in the area of foods and other basic essentials, the provisions were largely insufficient and poorly distributed. For example, the Nigerian government released the huge sums of money through the Social Investment Programme (SIP) to support 3.6 million poor households in the country with an estimated population of over 200 million.

The virus has further exposed the comatose state of public health system in West Africa. The hospitals lack the equipment needed to manage COVID-19 because there are little or no ventilators, suture machines, testing kits and protective gears for health workers. The health system has been in a state of disrepair and total neglect for years because most African leaders and politicians prefer to go on health pilgrimage in hospitals in the developed countries of the world. However, with the lockdown and travel bans initiated to curb the spread of the virus, the inadequacy of the local health facilities to cope with the pandemic became obvious. Amidst the health crises, most countries in Europe and America evacuated their citizens from African countries in order to protect them from contracting the 
virus and ensure that they can access the best healthcare available should they be infected. But Africans were left to the stark reality of a failed health system.

\section{Post COVID-19 Recovery Strategies for West African States}

From all indications, COVID-19 has changed the world as we knew it and things can never return to status quo. The COVID-19 pandemic has ravaged the economy of nations and influenced major changes in education, politics, communication, and lifestyles across the world. Recovery from the pandemic will be a strenuous journey without proper planning and nations will need to devise strategies to adapt otherwise they will be submerged in the Post COVID-19 era. Recovery efforts in West Africa states should be gradual, strategic and focused on bridging the gaps in healthcare delivery, education, economy, and polity that were exposed by the pandemic. For example, in Nigeria, the head of the Presidential Task Force (PTF) on COVID-19 and Secretary to the Government of the Federation (SGF), Boss Mustapha, publicly admitted that he was not aware that the Nigerian health system had totally collapsed until the tour of hospitals in the country on PTF duties (Igomu, 2020).

Still on the health sector, there are shortages of ventilators and other medical essentials across West Africa. Also, data collation and response to medical emergencies during the lockdown was very poor mostly because there was no existing data base and little or no testing kits in most of the countries in the sub-region. Efforts in Europe, Asia and America at combating the virus included massive testing for the virus, building of huge medical facilities in record time and conducting researches to develop effective vaccines to stop the virus. However, most countries in West African seemed to be overwhelmed and resulted to the use of political solutions such as strict restrictions in people's movement to slow the spread of the pandemic. There were individual and government-supported efforts in Ghana, Nigeria and other West African states to sew or produce facemasks in large scale using African fabrics. The sale of these locally produced facemasks created a boom in the textile industry. ,

Therefore, in post COVID-19 era, West African states should invest more in local industries and shun unnecessary importation in order to effectively manage whatever is left of the economy after the virus. The International Monetary Fund (2020) posits that economic diversification into sectors such as mining, manufacturing, agriculture, textile and youth entrepreneurship schemes is capable of facilitating economic recovery instead of a oneway economy which is the case with most countries in the sub-region before the outbreak of the pandemic. For postpandemic economic recovery in the sub-region, ECOWAS must support small and medium scale industries through aids that will increase productivity and industrialization in West Africa.

The lockdown on movement of people in West African states has increased the use of online channels for business transactions, POS mode of payment and home delivery services. Despite massive unemployment rates in the sub-region before the pandemic, the use of home delivery services during the lockdown has proved that it can be rebranded and adopted as viable employment generation machinery for member states. The need to continue the cashless means of transactions in post-pandemic West African states is important for economic recovery and the survival of small businesses in the sub-region.

With the closure of schools during the pandemic, teaching and learning activities were conducted using technology and streamed live or viewed through uploaded pre-recorded videos and audios. Online learning and eLecture materials were available to students to engage them and ensure that though schools were closed, learning remained open and accessible. In countries like Nigeria, Burkina Faso, Senegal and the Gambia, state-owned television and radio channels were deployed for instructional purposes. Also, most schools (public and privateowned) compelled their teachers to make use of computers and common social media tools such as YouTube, Whatsapp and Facebook to teach their students during the lockdown. The implication of this is that the ICT and technology will play more prominent roles in education after the COVID-19 outbreak.

Nations within the ECOWAS need to work together to recover from the negative effects of the COVID-19 pandemic on the economy, education, polity, lifestyles and socio-economic status in the sub-region. Government policies should be home-grown to address the numerous local problems within the sub-region. Africans should learn their lessons and invest in their homelands by building world class health facility with sophisticated investments. The most important palliative any reasonable government can provide for its people is empowerment. Therefore, local industries should be supported to grow and the establishment of new industries should be encouraged. Youths in the sub-region should be empowered through capacity building programmes and training in relevant IT skills that can make them contribute immensely to the $21^{\text {st }}$ century technology-driven economy.

Plugs should be applied to the holes in the system to put an end to the problem of brain -drain in the sub-region. Flexibility should be allowed in the conventional system of education so that eLearning tools can be maintained in the Post-pandemic era. This will require that huge investment should be made into the education and teacher-training problems to accommodate the change. Agriculture and the provision of food should be the primary concern of all the responsible governments in the West African states and the poor and vulnerable should be at the centre of the government's policy to eradicate hunger and poverty. Households should be encouraged to grow and keep a garden to sustain the fight against hunger and manage their own palliatives. Due to the pandemic, the human world has evolved considerably and it is obvious that the world cannot remain the way they were before COVID-19 even after the virus is conquered. Therefore, all the recovery strategies for West African states after the outbreak of the COVID-19 pandemic should be established on increase in the use technology in education, commerce, socioeconomic and political activities. 


\section{Conclusion and Recommendations}

COVID-19 pandemic has changed the world we live in drastically. Attempts to contain the spread of the virus and flatten the curves in the number of deaths and infected cases have seen governments globally and in West African states place strict restrictions such as travel bans, social distancing, lockdown of public institutions like schools, shopping malls, religious worship centres and so on. These measures have had dire consequences on education, socio-economic and political activities, and the people's lifestyle. The pandemic has exposed the terrible state of health care facilities and the height of poverty in the sub-region. However, technology has been massively employed to keep the system together through eLearning, POS transactions, information dissemination and religious activities are streamed live through social media tools. Also, local industries have emerged through the lockdown to produce tons of facemasks and home delivery service is booming in spite of the imposed lockdown and curfews. Therefore, this paper argued that technology should be retained as an integral aspect of the Post COVID-19 recovery strategies in West African states.

Therefore, the following recommendations are made to aid post-pandemic recovery plans of ECOWAS member states:

1. All the countries in the sub-region must work together.

2. The integration of technology into educational and socio-economic activities should be sustained after the outbreak.

3. ECOWAS should advocate, support and encourage its member states to adopt E-government in the post COVID era.

4. ECOWAS member states should follow the Nigerian example and embrace cashless policies in financial transactions.

5. Youth empowerment, agriculture and the development of cottage industries must be prioritized for economic recovery in the Post COVID-19 era.

6. The West African health care system should be overhauled and revamped to avoid unnecessary loss of precious lives.

7. Strict hygiene measures and lifestyles should be continued until it becomes a culture.

\section{References}

Adesanya, A. (2020). POS Transaction rise 70\% in March 2020. Available: www.businesspost.ng

Africa Centre for Disease Control (2020). Latest updates on the COVID-19 from Africa CDC. Available: https://africacdc.org/covid-19/

BBC News (2020). Corona virus: Nigeria Confirm first case in Sub-Saharan Africa. Available: https://www.bbc.com/news/world-africa-51671834

Devecioglu, K. (2020). COVID-19 Pandemic: Great danger Awaits Africa. Available: https://www.aa.com.tr/en/africa/analysis-covid-19-pandemic-great-danger-awaits-africa/1789840

Hanafi, A. (2020). COVID-19: US, Nigeria, Iran and others release detainees, prisoners. The Punch Newspaper online, April 5.

Igomu, T. (2020). I didn't Know Nigeria's Health Sector was this bad-Boss Mustapha. Punch Healthwise. https://heathwise.punchng.com/i-didn't-know-nigeria's-health-sector-was-this-bad-boss-mustapha/

International Monetary Fund (2020). African growth set to suffer as coronavirus outbreak cuts demand, African Economy. Financial Times. https://www.ft.com/content/f5d1d240-524b-11ea-90ad-25e377c0ee1f

Karaki, K. and Verhaeghe, E., 2017. "Understanding ecowas trade policy and trade facilitation advancing economic integration one hurdle at a time." In European Center for Development Policy Management Background Paper. p. 15.

Maclean, R. (2020). African braces for Coronavirus, but slowly. The New York Times.

Rumours and Facts (2020). Rumours and facts on COVID-19. (2): Available: https://www.who.int/emergencies/diseases/novel-coronavirus-2019/advice-for-public/myth-busters

United Nations Office on Drugs and Crime (2020). Available: https://www.unodc.org/unodc/en/covid-19.html

United Nations Women (2020). Africa COVID-19 and the link to violence and girls. Available: www.africa.unwomen.org 